\title{
Identification and regulation of glycogen synthase kinase-3 during bovine embryo development
}

\author{
I M Aparicio, M Garcia-Herreros, T Fair and P Lonergan \\ School of Agriculture, Food Science and Veterinary Medicine, College of Life Sciences, Veterinary Sciences Centre, \\ University College Dublin, Belfield, Dublin 4, Ireland \\ Correspondence should be addressed to P Lonergan; Email: pat.lonergan@ucd.ie
}

\begin{abstract}
The aim of this study was to examine the presence and regulation of glycogen synthase kinase-3 $\alpha$ (GSK3A) and GSK-3 $\beta$ (GSK3B) in bovine embryos and their possible roles in embryo development. Our results show that GSK3A and GSK3B are present in bovine embryos at the two-cell stage to the hatched blastocyst stage. Bovine embryo development was associated with an increase in the phosphorylation of both isoforms, being statistically significant at blastocyst and hatched blastocyst stages, compared with earlier stages. Inhibition of GSK3 with СТ99021 $(3 \mu \mathrm{M})$ resulted in a significant increase in the percentage and quality of blastocysts, while inhibition of GSK3 with lithium chloride ( $\mathrm{LiCl} ; 20 \mathrm{mM}$ ) significantly reduced at the proportion of eight-cell embryos on day 3 and inhibited blastocyst formation. The use of LY294002 (10 $\mu \mathrm{M})$, a specific inhibitor of phosphatidylinositol-3 kinase, also produced a significant decrease in embryo development. In addition, treatment with $\mathrm{LiCl}$ and LY294002 produced a significant decrease in the serine phosphorylation of both isoforms of GSK3. Finally, CT99021 and LiCl reduced the phosphorylation of $\beta$-catenin on Ser45 in two-cell embryos, while LY294002 increased it. Despite the fact that $\mathrm{LiCl}$ inhibited GSK3 activity, as demonstrated by $\beta$-catenin phosphorylation, its effects on the bovine embryo could be mediated through other signaling pathways leading finally to a decrease in the phosphorylation of GSK3 and a reduction in embryo development. Therefore, in conclusion, GSK3A/B serine phosphorylation was positively correlated with embryo development, indicating the importance of an accurate regulation of GSK3 activity during developmental stages to achieve normal bovine embryo development. Reproduction (2010) 140 83-92
\end{abstract}

\section{Introduction}

Glycogen synthase kinase-3 (GSK3) is a highly evolutionary conserved intracellular serine-threonine kinase which exists as two isoforms, GSK-3 $\alpha$ (GSK3A) and GSK-3 $\beta$ (GSK3B), ubiquitously expressed in mammalian tissues (Woodgett 1990). The isoforms share 97\% sequence similarity within their kinase catalytic domain, but differ significantly outside this region, with GSK3A possessing an extended $\mathrm{N}$-terminal glycine-rich tail (Woodgett 1990). GSK3 is constitutively activated in mammals, but its activity is significantly reduced by the phosphorylation of an N-terminal serine, Ser9 in GSK3B and Ser21 in GSK3A (Frame et al. 2001). Phosphorylation, and therefore inactivation of GSK3, can be catalyzed by insulin, growth factors, and amino acids throughout phosphatidylinositol-3 kinase (PI3K)/AKT, MAPK cascade, protein kinase C (PKC), or by cAMPdependent protein kinase/protein kinase A (PKA; Goode et al. 1992, Fang et al. 2000, Frame \& Cohen 2001).

Originally identified as a regulator of glycogen metabolism throughout the classical PI3K/AKT signaling pathway (Frame \& Cohen 2001), GSK3 regulates a diverse array of cell functions including protein synthesis, cell proliferation, cell differentiation, apoptosis, microtubule dynamics, and cell motility. It has been recently described that GSK3B may regulate oocyte meiosis, in particular the metaphase-I/II transition, being part of the MAPK3/1 and MAPK14 pathways in oocytes and cumulus cells in cattle (Uzbekova et al. 2009). GSK3 has been demonstrated to be a key regulator of cellular fate and a participant in the differentiation events during embryonic development through its participation in the Wnt signal transduction pathway (reviewed in Forde \& Dale (2007)). GSK3 phosphorylates $\beta$-catenin, the central component in Wnt signaling which is responsible for the transmission of Wnt signals to the nucleus. Phosphorylation of $\beta$-catenin by GSK3B leads to ubiquitination of $\beta$-catenin and its subsequent degradation in proteasomes. However, when GSK3B is inactivated by phosphorylation, $\beta$-catenin translocates into the nucleus and stimulates the transcription of Wnt genes (Aberle et al. 1997). It has been shown that there is a correlation between a proper regulation of Wnt signaling and normal embryo development. For example, bovine embryos which develop past the 16 -cell stage showed a proper distribution of $\beta$-catenin in all blastomeres and an appropriate morphology 
(Modina et al. 2007). However, the deletion of certain Wnt genes in the mouse, Caernorhabditis elegans, and Drosophila results in strong changes in the phenotypes (Cadigan \& Nusse 1997).

Lithium, one of the most effective drugs for the treatment of bipolar disorder, exerts its effects through the inhibition of GSK3 (Klein \& Melton 1996) by two mechanisms that act in concert. First, there is a direct inhibitory effect by lithium on GSK3 through competition with magnesium ions for binding to GSK3. Secondly, lithium causes indirect inhibition of GSK3 by increasing the inhibitory serine phosphorylation of GSK3 (reviewed in Jope (2003)). Lithium can mimic the actions of $W n t / W i n g l e s s$ on $\beta$-catenin/Armadillo in mammalian and Drosophila cells (Stambolic et al. 1996). Treatment with lithium has dramatic effects on morphogenesis during early development of diverse organisms. In zebrafish, lithium exposure produces excessive shield formation and extreme hyper-dorsal development (Stachel et al. 1993). In Xenopus, it causes an expansion of dorsal mesoderm, leading to duplication of the dorsal axis or, in extreme cases, entirely dorsalized embryos (Kao et al. 1986). A short treatment with lithium chloride ( $\mathrm{LiCl})$ at the two- or eight-cell stage causes mouse embryos to develop axial defects similar to those observed in some mutations that adversely affect gastrulation (Rogers \& Varmuza 1996).

Repeated mitosis during embryonic cleavage requires a careful regulation of microtubule dynamics for assembling a spindle apparatus that accurately segregates chromosomes. In somatic cells, Wakefield et al. (2003) reported that GSK3 is present along the length of spindle microtubules, being phospho-GSK3 abundant at the centrosome and spindle poles. Furthermore, inhibition of GSK3 leads to an increase in the length of mitotic microtubules and defective chromosome alignment, suggesting that GSK3 activity is involved in regulating the balance of microtubule dynamics during mitosis (Wakefield et al. 2003). In C. elegans embryos, GSK3 has been shown to act positively to promote both endoderm specification and proper mitotic spindle orientation via the Wnt pathway (Schlesinger et al. 1999).

Therefore, given the importance of GSK3 during embryo development through the Wnt pathway and the lack of information on the role of GSK3 in mammalian embryos, the aims of this study were to examine the presence and regulation of both isoforms of GSK3 during early bovine preimplantation development and to study the role of GSK3 in embryo development by its inhibition using two inhibitors: LiCl and CHIR99021 (CT99021). The mechanism of lithium action on GSK3 activity is well studied (Jope 2003). The aminopyrimidine CHIR99021 is a cell-permeable compound that acts as potent, ATP-competitor, and is one the most selective inhibitors of GSK3 reported to date (Ring et al. 2003, Meijer et al. 2004). Finally, we aimed to study the relationship of GSK3 to the PI3K and Wnt signaling pathways using LY294002 (2-(4-morpholinyl)8-phenyl-4H-1-benzopyran-4-one), which is a potent and specific cell-permeable inhibitor of PI3K (Vlahos et al. 1994). LY294002 competitively inhibits ATP binding to the catalytic subunit of PI3K.

\section{Results \\ GSK3 identification and regulation during early embryo development}

Anti-GSK3A and anti-GSK3B antibodies detected two bands of $\sim 51$ and $46 \mathrm{kDa}$ respectively in bovine cumulus cells, used as positive samples (Uzbekova et al. 2009), and in two-cell embryos (Fig. 1A). The same antibodies detected the total form of GSK3A and GSK3B in two- and eight-cell embryos, morulae, and blastocysts, demonstrating the presence of GSK3 throughout early bovine embryo development (Fig. 1B). Serine phosphorylation of GSK3A and GSK3B was also studied during embryo development using two specific antibodies. Antibodies detected two protein bands of 51 and $46 \mathrm{kDa}$ corresponding to the phosphorylated form of GSK3A and GSK3B respectively in bovine oocytes before and after in vitro maturation (IVM), used as positive samples (Uzbekova et al. 2009), and in two-cell embryos (Fig. 2A). Results showed an increase in the phosphorylated form of both isoforms, indicative of an inactivation, as embryo development progressed, being statistically significant at the blastocyst and hatched blastocyst stages compared with earlier stages of development (Fig. 2).

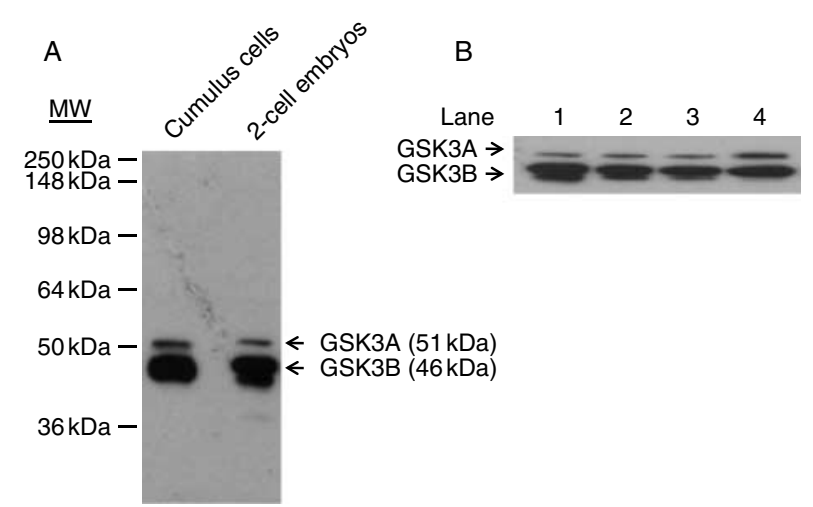

Figure 1 GSK3 identification in bovine embryos. (A) Bovine cumulus cells were used as a positive control to study the specificity of the antibodies against the total form GSK3A and GSK3B. (B) Proteins extracted from cumulus cells and proteins from embryos (35 per lane) at the two-cell (lane 1), eight-cell (lane 2), morula (lane 3), and blastocyst (lane 4) stages were loaded and resolved by SDS-PAGE in a $10 \%$ acrylamide gel. Immunoblotting was performed using two specific antibodies against the total forms of GSK3A or GSK3B $(n=3)$. MW, molecular weight. 


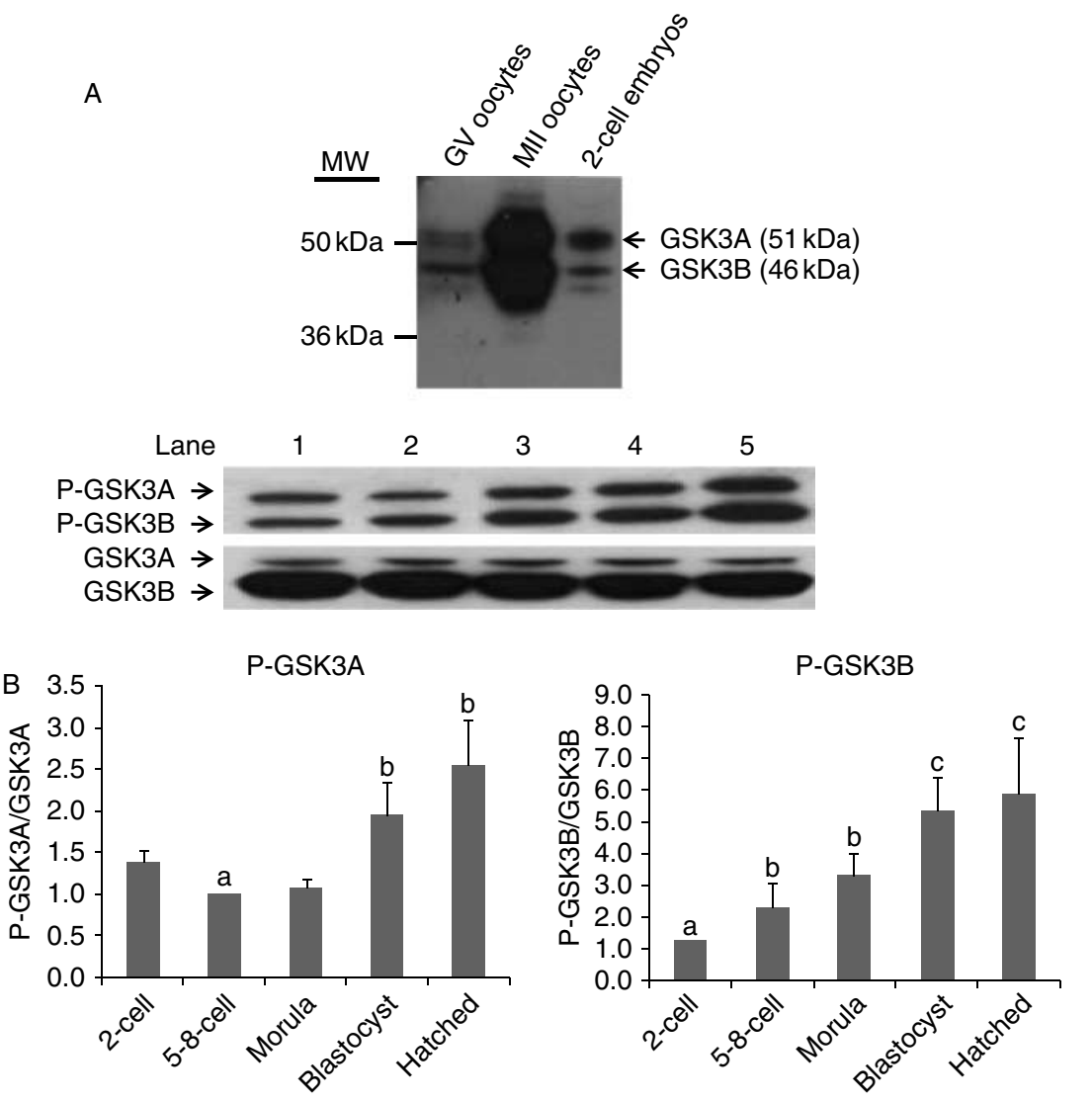

Figure 2 GSK3 phosphorylation during early bovine embryo development. (A) Bovine immature and mature oocytes were used as a positive control to study the specificity of two antibodies against the phosphorylated form of GSK3A or GSK3B.

(B) Proteins extracted from oocytes (40 per lane) and embryos (35 per lane) at the two-cell (lane 1), eight-cell (lane 2), morula (lane 3), blastocyst (lane 4), and hatched blastocyst (lane 5) stages were loaded and resolved by SDS-PAGE in a $10 \%$ acrylamide gel. Immunoblotting was performed using two specific antibodies against the phosphorylated form of GSK3A or GSK3B. Densitometry of protein bands was measured and represented as ratios of phosphoprotein kinase/total protein kinase $(n=4)$. Columns marked with different letters indicate significant differences $(P<0.05)$. MW, molecular weight.

\section{Effect of GSK3 inhibition on embryo development and quality}

Given that GSK3 activity is regulated during embryo development, we aimed to study the effect of GSK3 inhibition using two inhibitors, $\mathrm{LiCl}(20 \mathrm{mM})$ and CT99021 $(3 \mu \mathrm{M})$. Concentrations chosen for each inhibitor were based on previous studies ( $\mathrm{Li}$ et al. 2008, Uzbekova et al. 2009). Treatment of presumptive zygotes with CT99021, a well-characterized highly selective small molecule inhibitor of GSK3 (Murray et al. 2004), produced a significant increase in the proportion of embryos reaching the blastocyst stage at days $7(31 \pm 1.58)$ and $8(38 \pm 4.71)$, compared with control embryos $(23 \pm 2.93,24 \pm 4.38$ respectively), in which only the vehicle (DMSO) was added (Table 1). Moreover, the number of cells observed in blastocysts and hatched blastocysts at day 8 were higher after treatment with CT99021 than in control embryos (Fig. 3). In contrast to the observations with CT99021, incubation of presumptive zygotes with $20 \mathrm{mM} \mathrm{LiCl}$ resulted in a lower cleavage rate, a significant decrease in the number of five- to eight-cell embryos at day 3 (29 \pm 5.70$)$ compared with control embryos $(53 \pm 3.98)$ and complete failure of embryos to reach the blastocyst stage (Table 2).

\section{Effect of PI3K inhibition on embryo development and quality}

To study the effect of PI3K inhibition on embryo development, presumptive zygotes were incubated with $10 \mu \mathrm{M}$ LY294002, a specific inhibitor of PI3K.

Table 1 Effect of glycogen synthase kinase-3 inhibition by CT99021 (3 $\mu \mathrm{M})$ on bovine embryo development in vitro. Results are expressed as a percentage of the total number of zygotes $(n=5)$.

\begin{tabular}{|c|c|c|c|c|c|c|}
\hline \multirow[b]{2}{*}{ Treatment } & \multirow[b]{2}{*}{$N$ zygotes } & \multirow[b]{2}{*}{$\%$ Cleaved at day 2} & \multirow[b]{2}{*}{$\begin{array}{l}\% \text { Five- to eight-cell } \\
\text { embryos at day } 3\end{array}$} & \multicolumn{3}{|c|}{$\%$ Blastocyst stage } \\
\hline & & & & Day 6 & Day 7 & Day 8 \\
\hline Control & 232 & $83 \pm 4.35$ & $52 \pm 4.30$ & $15 \pm 3.23$ & $23 \pm 2.93^{\mathrm{a}}$ & $24 \pm 4.38^{\mathrm{a}}$ \\
\hline СТ99021 (3 $\mu \mathrm{M})$ & 227 & $88 \pm 2.44$ & $59 \pm 3.70$ & $18 \pm 4.11$ & $31 \pm 1.58^{\mathrm{b}}$ & $38 \pm 4.71^{b}$ \\
\hline
\end{tabular}

Data marked with different letters indicate significant differences $(P<0.05)$ compared with the control. 


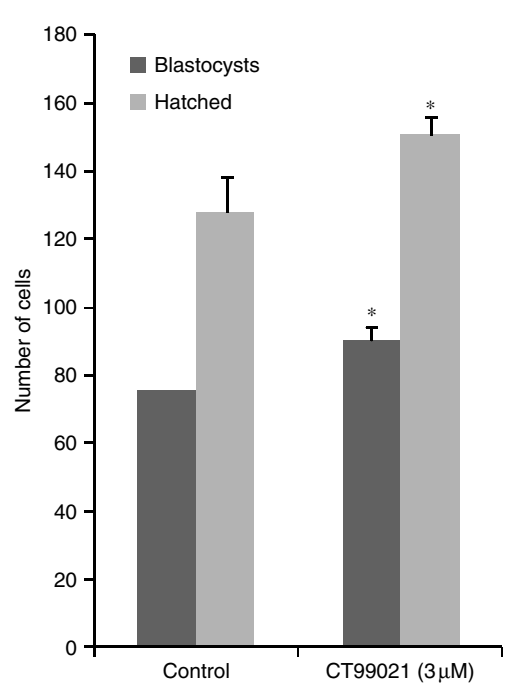

Figure 3 Effect of GSK3 inhibition on bovine embryo quality. To assess embryo quality, day 8 blastocysts produced in the absence or in the presence of $3 \mu \mathrm{M}$ CT99021 were washed in PBS, fixed in ethanol overnight at $4{ }^{\circ} \mathrm{C}$, and stained with Hoechst 33342 at $25 \mu \mathrm{g} / \mathrm{ml}(n=5)$. Columns marked with an asterisk $(*)$ indicate significant differences $(P<0.05)$ compared with controls.

Treatment with LY294002 leads to a decrease in cleavage rate $(56 \pm 5.23)$ at $48 \mathrm{~h}$ post insemination, a significant decrease in the proportion of five- to eight-cell embryos at day $3(20 \pm 2.17)$, and an almost complete inhibition of blastocyst development. The cell numbers in the few blastocysts that did form in the presence of the inhibitor were significantly lower than in control blastocysts (Fig. 4).

\section{Regulation of serine phosphorylation of GSK3A/B after GSK3 and PI3K inhibition}

Culture of embryos in the presence of $\mathrm{LiCl}(20 \mathrm{mM})$ resulted in a significant decrease in phosphorylated form of GSK3A and GSK3B compared with control embryos. In contrast, CT99021 $(3 \mu \mathrm{M})$ had no effect on GSK3 phosphorylation. However, when two-cell embryos were treated for $3 \mathrm{~h}$ with LY294002 $(10 \mathrm{mM})$, a significant decrease in the phosphorylated GSK3 form of both isoforms was observed (Fig. 5).

\section{$\beta$-Catenin phosphorylation: detection in bovine embryos and regulation of Ser45 phosphorylation by LiCl, CT99021, and LY294002}

Because $\beta$-catenin can be regulated by phosphorylation at different residues, we aimed to study all of them using specific antibodies that recognize $\beta$-catenin phosphorylated at Threonine 41, Ser33 and Ser37, Ser45, Ser552, and Ser675. $\beta$-Catenin was phosphorylated in day 8 bovine blastocysts on all residues mentioned above except those which are directly phosphorylated by GSK3 (Thr41 and Ser33/37; Fig. 6). Despite the differences in the degree of phosphorylation detected by the antibodies, we aimed to study the phosphorylation at Ser45 because it is necessary for subsequent phosphorylation of $\beta$-catenin by GSK3. Results showed a decrease in the quantity of $\beta$-catenin phosphorylated on Ser45 after inhibition of GSK3 with $\mathrm{LiCl}$ and CT99021, but an increase after inhibition of PI3K (Table 3).

\section{Discussion}

We have demonstrated for the first time that bovine embryos express both GSK3A and GSK3B isoforms from the two-cell stage to the blastocyst stage. The phosphorylation of both isoforms increased as development progressed, suggesting that the inhibition of GSK3 and the signaling pathway mediated by this protein are associated with normal embryo development. The presence of GSK3 has been recently described in bovine oocytes and cumulus cells (Uzbekova et al. 2009). The same authors showed that GSK3B may regulate oocyte meiosis, in particular the metaphase-I/II transition, being part of MAPK3/1 and MAPK14 pathways in oocytes and cumulus cells in cattle (Uzbekova et al. 2009). Therefore, GSK3 present before the maternal to embryonic transition is likely to be of maternal origin (i.e. stored in the oocyte; Vigneault et al. 2004).

Most of the roles described for GSK3 in embryonic development are through its participation in the Wnt signal transduction pathway (reviewed in Forde \& Dale (2007)) phosphorylating $\beta$-catenin. Phosphorylation of $\beta$-catenin is regulated by different kinases: GSK3 which phosphorylates at residues Threonine 41, Ser33, and Ser37 (Yost et al. 1996); CK1 which phosphorylates at Ser45, priming $\beta$-catenin for subsequent phosphorylation

Table 2 Effect of glycogen synthase kinase-3 inhibition by lithium chloride ( $\mathrm{LiCl} ; 20 \mathrm{mM}$ ) on bovine embryo development in vitro. Results are expressed as a percentage of the total number of zygotes $(n=4)$.

\begin{tabular}{|c|c|c|c|c|c|c|}
\hline \multirow[b]{2}{*}{ Treatment } & \multirow[b]{2}{*}{$N$ zygotes } & \multirow[b]{2}{*}{$\%$ Cleaved at day 2} & \multirow[b]{2}{*}{$\begin{array}{l}\% \text { Five- to eight-cell } \\
\text { embryos at day } 3\end{array}$} & \multicolumn{3}{|c|}{$\%$ Blastocyst stage } \\
\hline & & & & Day 6 & Day 7 & Day 8 \\
\hline Control & 194 & $81 \pm 3.31$ & $53 \pm 3.98^{\mathrm{a}}$ & $9 \pm 1.53^{\mathrm{a}}$ & $17 \pm 1.66^{\mathrm{a}}$ & $24 \pm 2.07^{\mathrm{a}}$ \\
\hline $\mathrm{LiCl}(20$ mM) & 193 & $69 \pm 7.24$ & $29 \pm 5.70^{b}$ & $0 \pm 0.00^{b}$ & $0 \pm 0.00^{b}$ & $0 \pm 0.00^{b}$ \\
\hline
\end{tabular}

Data marked with different letters indicate significant differences $(P<0.05)$ compared with the control. 


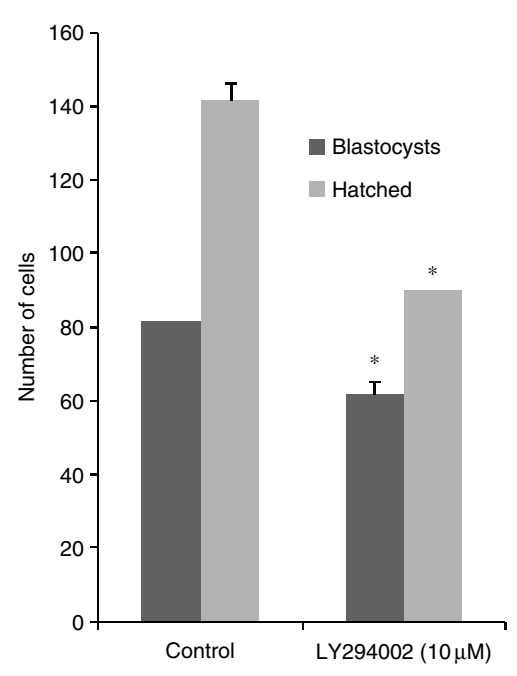

Figure 4 Effect of PI3K inhibition on bovine embryo quality. To assess embryo quality, day 8 blastocysts produced in the absence or in the presence of $10 \mu \mathrm{M}$ LY294002 were washed in PBS, fixed in ethanol overnight at $4{ }^{\circ} \mathrm{C}$, and stained with Hoechst 33342 at $25 \mu \mathrm{g} / \mathrm{ml}(n=4)$. Columns marked with an asterisk $(*)$ indicate significant differences $(P<0.05)$ compared with controls.

by GSK3 (Amit et al. 2002, Yanagawa et al. 2002); AKT and PKA which phosphorylate at Ser552 and Ser675 (Hino et al. 2005, Taurin et al. 2006, Fang et al. 2007). $\beta$-Catenin was phosphorylated in bovine embryos on all residues mentioned above except those which are directly phosphorylated by GSK3 (Thr41 and Ser33/37), indicating that phosphorylation of $\beta$-catenin on Ser 45 in bovine embryos precedes, and is required by, subsequent phosphorylation by GSK3. Despite the fact that $\beta$-catenin is phosphorylated on different residues, we focused this study on the phosphorylation on Ser45 as it is specific to GSK3 (Fig. 7).

It has been previously reported that lithium inhibits GSK3B activity and mimics the biochemical effect of Wnt signaling by leading to a decrease in the phosphorylation of $\beta$-catenin protein and its stabilization (Hedgepeth et al. 1997, Rao et al. 2005), which is consistent with the results of the present study. Also, a decrease in $\beta$-catenin phosphorylation was observed after treatment with CT9921, indicating that GSK3 activity was also inhibited. However, despite the fact that both GSK3 inhibitors inhibited GSK3 activity, the effects on embryo development were divergent; $\mathrm{LiCl}$ decreased the proportion of zygotes reaching the blastocyst stage, while CT99021 increased development. One of the mechanisms proposed for the actions of lithium in Xenopus embryos and bovine and mouse oocytes is through the direct inhibition of GSK3B (Klein \& Melton 1996, Hedgepeth et al. 1997, Wang et al. 2003, Uzbekova et al. 2009). However, lithium also caused a significant decrease in the phosphorylation of GSK3A and GSK3B, indicating activation of the protein. GSK3 has been described as being present in the cytosol, nucleus, and mitochondria (Bijur \& Jope 2003), and is capable of processing more than one stimulus and delivering distinct outcomes due to compartmentalization of its action within the cell (Harwood 2001). One plausible explanation for the results obtained here is that lithium is affecting different pools of GSK3 (Bijur \& Jope 2003), producing an inactivation of GSK3, which is reflected in the phosphorylation of $\beta$-catenin, and an activation of GSK3 through an inhibition of its phosphorylation and decreasing bovine embryo development. The decrease in GSK3 phosphorylation observed
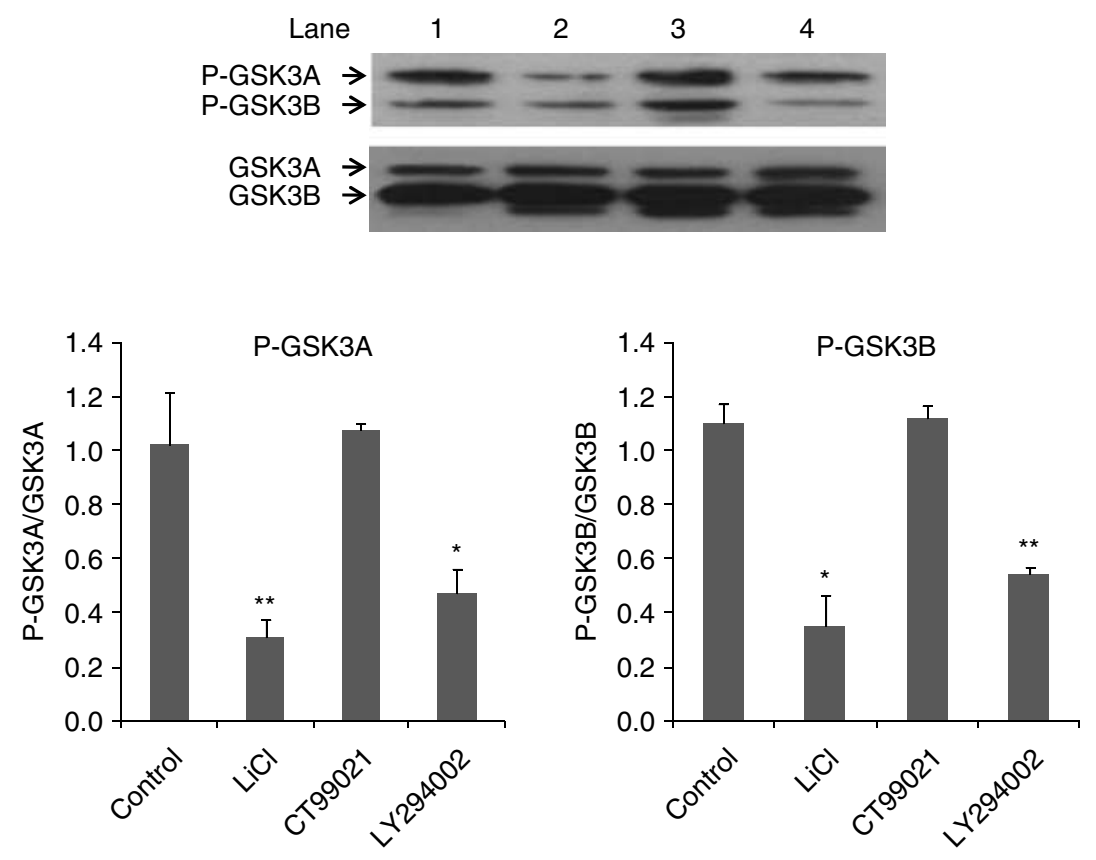

Figure 5 Effect of LiCl, CT99021 and LY294002 on GSK3 serine phosphorylation. To study the effect of GSK3 and PI3K inhibitors on GSK3 phosphorylation, two-cell embryos were treated with $\mathrm{LiCl}$ (lane 2), CT99021 (lane 3), or LY294002 (lane 4) for $3 \mathrm{~h}$. Subsequently, 35 embryos were loaded and resolved by SDS-PAGE in a $10 \%$ acrylamide gel. Immunoblotting was performed using two specific antibodies against the phosphorylated form of GSK3A or GSK3B. Densitometry of protein bands was measured and represented as ratios of phosphoprotein kinase/total protein kinase $(n=4)$. Columns marked with an asterisk(s) indicate significant differences compared with controls. ${ }^{*} P<0.05$; ${ }^{* *} P<0.01$. 
A

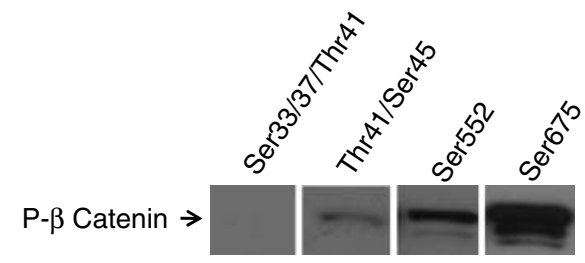

B
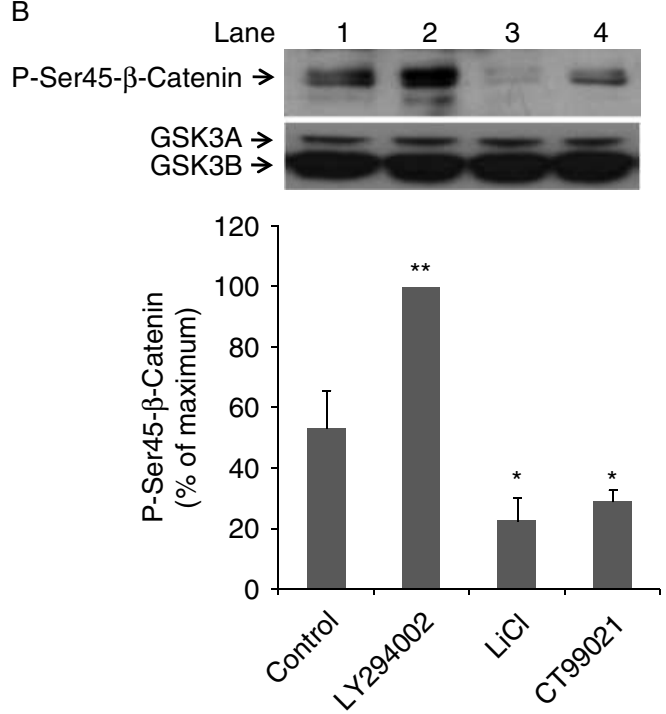

Figure $6 \beta$-Catenin phosphorylation and regulation by GSK3 and PI3K inhibition. (A) To study which residues were phosphorylated by $\beta$-catenin, 30 day 8 blastocysts were loaded and resolved by SDS-PAGE in a $10 \%$ acrylamide gel. Immunoblotting was performed using specific antibodies against $\beta$-catenin phosphorylated at Thr41, Ser33/37 (gel 1)-Thr41, Ser45 (gel 2)-Ser552 (gel 3) and Ser675 (gel 4). (B) To investigate the phosphorylation of $\beta$-catenin on Ser45, two-cell embryos after being treated with LY294002 (10 $\mu \mathrm{M}$; lane 2), LiCl (20 mM; lane 3), CT99021 (3 $\mu \mathrm{M}$; lane 4) for $3 \mathrm{~h}$ were loaded and resolved by SDS-PAGE in a $10 \%$ acrylamide gel. Immunoblotting was performed using the specific antibody against $\beta$-catenin phosphorylated at Thr41/Ser45. Densitometry of protein bands was measured and represented as percentage of maximum ( $n=4$ replicates). Columns marked with an asterisk(s) indicate significant differences compared with controls. ${ }^{*} P<0.05 ; * * P<0.01$.

after lithium treatment may be due to lithium action not only inactivating GSK3, but also inhibiting the actions of forskolin and dbcAMP (Bagger et al. 1993) and interacting directly with the catalytic unit of the adenylate cyclase system (Mork \& Geisler 1987, Manji et al. 1995) decreasing the concentration of cAMP.
Moreover, in germinal cells and in the bovine corpus luteum, an increase in the phosphorylation of GSK3 in response to agonists that elevate intracellular concentrations of cAMP has been demonstrated (Aparicio et al. 2007, Roy et al. 2009), showing the interaction of cAMP and GSK3 (Fang et al. 2000). Lithium also interferes with another second messenger system, the inositol pathway causing selective reductions of PKC (Manji \& Lenox 1999), which has been shown to phosphorylate and inactivate GSK3 mediating acentromeric spindle stabilization in mouse oocytes (Baluch \& Capco 2008). This reduction in CAMP concentration or PKC by lithium in bovine embryos would lead to a decrease in the phosphorylation of GSK3, as observed here, and may explain the detrimental effect on embryo development as previously shown in mouse, rabbit, and Xenopus embryos (Kao et al. 1986, Fahy \& Kane 1994, Rogers \& Varmuza 1996). In the present study, because both inhibitors reduced $\beta$-catenin phosphorylation, the detrimental effect of lithium on bovine embryo is mainly mediated through other signaling pathways leading finally to a decrease in the phosphorylation of GSK3 and a reduction in embryo development.

One of the most studied and best characterized intracellular pathway that produces the phosphorylation and activity downregulation of GSK3 is the PI3K/AKT pathway. Jousan \& Hansen (2007) and Jousan et al. (2008) demonstrated the presence of PI3K/AKT and its role in mediating the antiapoptotic effects of insulin-like growth factor 1 (IGF1) in bovine embryos. In the present work, treatment of presumptive zygotes with LY294002 produced a significant reduction in the phosphorylation of GSK3 together with a decrease in embryo development and quality. This decrease observed in bovine embryo development could be produced by an increase in apoptosis, as mentioned earlier, or by a $\mathrm{G}_{2} / \mathrm{M}$ arrest as showed previously in mouse embryos after silencing the catalytic subunit of PI3K (Xu et al. 2009). Although it is well known that the Wnt signal transduction pathway is activated by wnts, a family of secreted proteins that act on target cells in a paracrine fashion through members of frizzled receptor family (Seidensticker \& Behrens 2000), in the present study, inhibition of PI3K resulted in an increase in phosphorylation of $\beta$-catenin, suggesting a crosstalk between $\mathrm{PI} 3 \mathrm{~K}$ and $W n t$ signaling pathway. The increase in the phosphorylation of $\beta$-catenin would lead

Table 3 Effect of phosphatidylinositol-3 kinase inhibition with $10 \mu \mathrm{M}$ of LY294002 on bovine embryo development in vitro. Results are expressed as a percentage of the total number of zygotes $(n=4)$.

\begin{tabular}{|c|c|c|c|c|c|c|}
\hline \multirow[b]{2}{*}{ Treatment } & \multirow[b]{2}{*}{$N$ zygotes } & \multirow[b]{2}{*}{$\%$ Cleaved at day 2} & \multirow[b]{2}{*}{$\begin{array}{l}\% \text { Five- to eight-cell } \\
\text { embryos at day } 3\end{array}$} & \multicolumn{3}{|c|}{$\%$ Blastocyst stage } \\
\hline & & & & Day 6 & Day 7 & Day 8 \\
\hline Control & 178 & $74 \pm 2.87^{\mathrm{a}}$ & $40 \pm 0.32^{\mathrm{a}}$ & $7 \pm 0.94^{a}$ & $22 \pm 2.12^{\mathrm{a}}$ & $28 \pm 1.58^{\mathrm{a}}$ \\
\hline LY294002 $(10 \mu \mathrm{M})$ & 174 & $56 \pm 5.23^{b}$ & $20 \pm 2.17^{b}$ & $0 \pm 0.00^{b}$ & $4 \pm 1.54^{b}$ & $9 \pm 2.17^{b}$ \\
\hline
\end{tabular}

Data marked with different letters indicate significant differences $(P<0.05)$ compared with the control. 


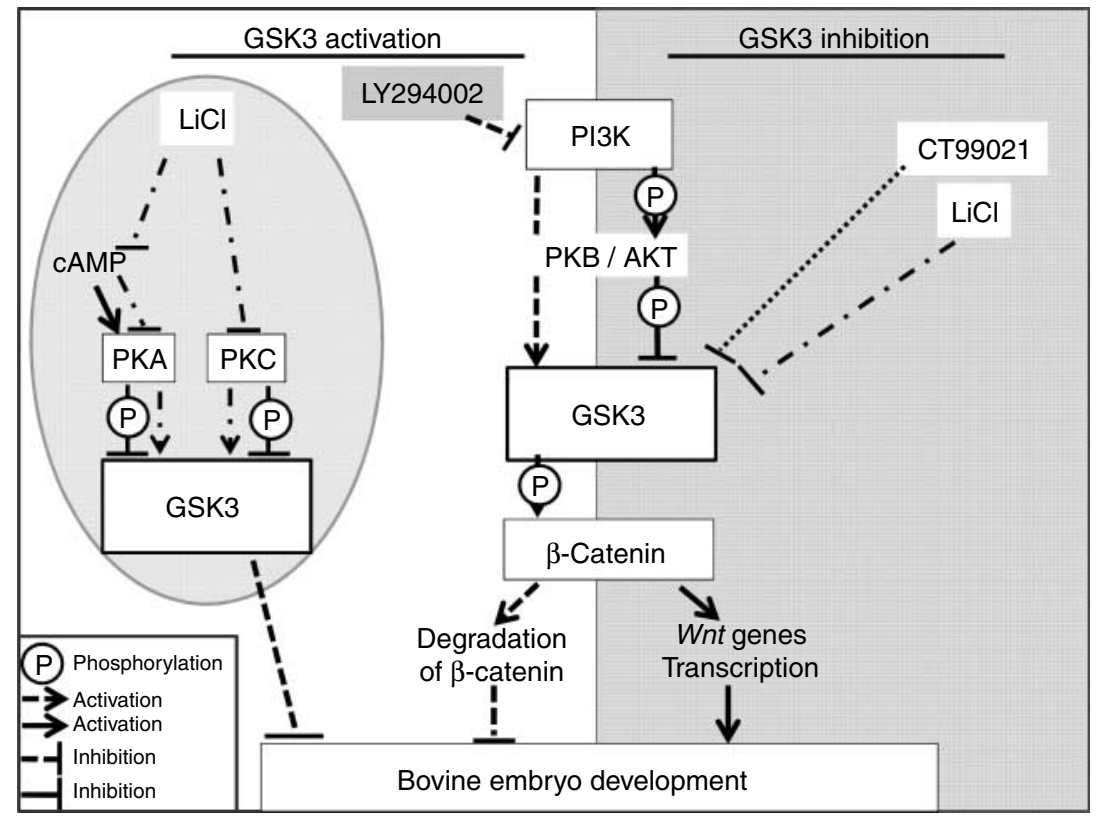

Figure 7 Proposed model of involvement of GSK3 in bovine embryo development. The inhibition of PI3K with LY294002 induced a decrease in GSK3 phosphorylation, activating it, which, subsequently phosphorylated $\beta$-catenin. Phosphorylation of $\beta$-catenin by GSK3 would lead to ubiquitination of the protein and its subsequent degradation in proteasomes, inhibiting bovine embryo development. However, when GSK3 is inactivated by $\mathrm{LiCl}$ and CT99021, $\beta$-catenin would translocate into the nucleus stimulating the transcription of Wnt genes, promoting bovine embryo development. However, $\mathrm{LiCl}$, apart from its effects on Wnt signaling pathway, simultaneously reduces the phosphorylation of GSK3, which could be mediated by a reduction of CAMP or inactivation of PKC, promoting the activation of GSK3 and inhibiting bovine embryo development. Continuous arrows, signaling in basal conditions; discontinuous arrows, signaling in the presence of inhibitors. to ubiquitination of $\beta$-catenin and its subsequent degradation in proteasomes, blocking the transcription of Wnt genes (Aberle et al. 1997) which are important for a normal embryo development (Cadigan \& Nusse 1997).

In summary, the results of the current study indicate a positive correlation between bovine embryo development and blastocyst quality and phosphorylation of GSK3A/B. Despite the fact that lithium inhibited GSK3 activity, as demonstrated by $\beta$-catenin phosphorylation, its effects on the bovine embryo are mainly mediated through other signaling pathways leading finally to a decrease in the phosphorylation of GSK3 and a reduction in embryo development. Specific inhibition of GSK3 by CT99021 resulted in a decrease in $\beta$-catenin phosphorylation and an increase in embryo development and quality. Finally, the inhibition of PI3K resulted in an activation of GSK3 and an increase in the phosphorylation of $\beta$-catenin together with a decrease in the proportion of embryos reaching the blastocyst stage and blastocyst cell number, suggesting an important cross-talk between $W n t$ and PI3K pathways in the regulation of bovine embryo development. In conclusion, the results show the importance of the correct regulation of both isoforms of GSK3 phosphorylation and activity to achieve a proper bovine embryo development.

\section{Materials and Methods}

\section{Materials}

TCM-199 culture medium, FCS, epidermal growth factor (EGF), and $\mathrm{LiCl}$ were purchased from Sigma; CT99021 (CHIR 99021, \#1386) from Axon Medchem BV (Groningen,
The Netherlands); LY294002 (\#440204) from Calbiochem (Darmstadt, Germany); GSK3A antibody (\#9338), GSK3B (27C10) rabbit mAb (\#9315), phospho-GSK3B (Ser9) (\#9323), phospho-GSK3A (Ser21) (\#9316), phospho- $\beta$-catenin (Ser33/37/ Thr41) (\#9561), phospho- $\beta$-catenin (Thr41/Ser45) (\#9565), phospho- $\beta$-catenin (Ser552) (\#9566), phospho- $\beta$-catenin (Ser675) (\#9567), anti-rabbit IgG, HRP-linked antibody (\#7074) were purchased from Cell Signaling (Beverly, MA, USA).

\section{In vitro embryo production}

\section{Cumulus-oocyte complex collection and IVM}

Immature cumulus-oocyte complexs (COCs) were obtained by aspirating follicles from the ovaries of cattle killed at a local abattoir. Good quality COCs were selected and washed two times in PBS containing $36 \mathrm{mg} / \mathrm{ml}$ pyruvate, $50 \mathrm{mg} / \mathrm{ml}$ gentamycin, and $0.5 \mathrm{mg} / \mathrm{ml} \mathrm{BSA}$, followed by a final wash in maturation medium. Groups of up to 50 COCs were placed in 500-ml maturation medium (TCM-199 supplemented with $10 \%(\mathrm{v} / \mathrm{v}) \mathrm{FCS}$ and $10 \mathrm{ng} / \mathrm{ml}$ EGF) in a four-well dish and cultured at $39^{\circ} \mathrm{C}$ for $24 \mathrm{~h}$ in a humidified atmosphere containing $5 \% \mathrm{CO}_{2}$.

\section{IVF and in vitro culture}

Matured COCs were washed four times in PBS, and then placed in wells containing $250 \mu \mathrm{l}$ of fertilization medium. The fertilization medium consisted of Tyrode's medium with $25 \mathrm{mM}$ bicarbonate, $22 \mathrm{mM}$ Na-lactate, $1 \mathrm{mM}$ Na-pyruvate, $6 \mathrm{mg} / \mathrm{ml}$ fatty acid-free BSA, and $10 \mu \mathrm{g} / \mathrm{ml}$ heparin-sodium salt (184 units/mg heparin; Calbiochem, San Diego, CA, USA) per well. Each well was inseminated with frozen-thawed Percollseparated bull sperm (GE Healthcare Bio-Sciences, Uppsala, Sweden) at a concentration of $1 \times 10^{6}$ spermatozoa $/ \mathrm{ml}$. 
Plates were incubated for $24 \mathrm{~h}$ at $39{ }^{\circ} \mathrm{C}$ under an atmosphere of $5 \% \mathrm{CO}_{2}$ in air with maximum humidity.

At $\sim 20-h$ post fertilization, presumptive zygotes were denuded by gentle vortexing, washed three times in PBS and twice in culture medium before being transferred to $500 \mu \mathrm{l}$ of synthetic oviduct fluid +5\% FCS (Holm et al. 1999). Dishes were incubated at $39{ }^{\circ} \mathrm{C}$ under an atmosphere of $5 \% \mathrm{CO}_{2}, 5 \%$ $\mathrm{O}_{2}$, and $90 \% \mathrm{~N}_{2}$ with maximum humidity. Cleavage rate was recorded on day 2 (48-h post insemination), the proportion of eight-cell embryos was recorded on day 3 , and the proportion of embryos reaching the blastocyst stage was recorded on days 6-8 (day $0=$ day of IVF).

\section{Western blotting}

To separate the proteins according to their apparent molecular mass, SDS-PAGE was performed according to Laemmli (1970). Immature $(n=40)$ and mature oocytes $(n=40)$ were denuded of their cumulus investments by gentle pipetting and repeated washing in PBS, and the cumulus cells were recovered for analysis by centrifugation. Cumulus cells, oocytes, and embryos were resuspended in lysis buffer (M-PER Mammalian Protein Extraction Reagent; \#78503; Thermo Scientific, Rockford, IL, USA), supplemented with protease and phosphatase inhibitors (Halt protease inhibitor cocktail EDTA-free and Halt phosphatase inhibitor cocktail, \#78415, \#78420; Pierce, Rockford, IL, USA), frozen and thawed three times to extract the proteins, and centrifuged for $1 \mathrm{~min}$ at $10000 \mathrm{~g}$ at $4{ }^{\circ} \mathrm{C}$. Proteins were denatured by boiling for $5 \mathrm{~min}$ at $95^{\circ} \mathrm{C}$ in loading buffer (Laemmli sample buffer, Bio-Rad Laboratories, Inc., \#161-0737) supplemented with 5\% mercaptoethanol. Proteins extracted were loaded and resolved by SDS-PAGE on a $10 \%$ polyacrylamide gel. Proteins were transferred to a nitrocellulose membrane which was blocked with blocking buffer (5\% nonfat dry milk in a Tris-buffered saline-Tween-20 (TBST) containing $10 \mathrm{mM}$ Trizma base, $100 \mathrm{mM} \mathrm{NaCl}$, and $0.5 \%$ Tween-20) for $1 \mathrm{~h}$ at room temperature. Immunoblotting was performed by incubating the membranes in blocking buffer overnight at $4{ }^{\circ} \mathrm{C}$ with primary antibodies. Membranes were subsequently washed in TBST and incubated with the appropriate species-specific HRP-conjugated secondary antibodies. Following three washes for $10 \mathrm{~min}$ each with TBST, the signal was visualized using SuperSignal West Pico Chemiluminescent Substrate kit (Pierce) according to the manufacturer's instructions.

\section{Experiment 1: GSK3 identification and regulation during early embryo development}

To study the specificity of the antibodies against the total and the phosphorylated form of GSK3A and GSK3B, bovine cumulus cells and oocytes (40 per lane) before and after IVM were used as positive samples (Uzbekova et al. 2009). Embryos (35 per lane) at the two-cell, five- to eight-cell, morula, blastocyst, and hatched blastocyst stages were loaded and resolved by SDS-PAGE in a $10 \%$ acrylamide gel. To identify GSK3, immunoblotting was performed using two specific antibodies against the total form of GSK3A and GSK3B $\left(1 / 1000\right.$ dilution, incubation overnight at $\left.4{ }^{\circ} \mathrm{C}\right)$. To study the regulation of both GSK3 during bovine embryo development, immunoblotting was performed using two specific antibodies that recognized phosphorylation at Ser21 and Ser9 of GSK3A and GSK3B respectively (1/1000 dilution, incubation overnight at $\left.4{ }^{\circ} \mathrm{C}\right)$.

\section{Experiment 2: effect of GSK3 inhibition on embryo development and quality}

To test the effect of GSK3 inhibition on embryo development and quality, in vitro-produced zygotes were cultured in the absence or in the presence of $20 \mathrm{mM}$ of $\mathrm{LiCl}(n=387$, four replicates) or $3 \mu \mathrm{M}$ of CT99021 $(n=459$, five replicates) added to the culture medium. Embryo cleavage rate was recorded at $48 \mathrm{~h}$ post insemination, the proportion of five- to eight-cell embryos was recorded on day 3 , and the proportion of blastocysts was recorded from day 6 to 8 . To assess embryo quality, day 8 blastocysts and hatched blastocyst produced in the absence or in the presence of GSK3 inhibitors were washed in PBS, fixed in ethanol overnight at $4{ }^{\circ} \mathrm{C}$, and stained with Hoechst 33342 at $25 \mu \mathrm{g} / \mathrm{ml}$. The number of cells was counted under a fluorescence microscope.

\section{Experiment 3: effect of PI3K inhibition on embryo development and quality}

To test the effect of PI3K inhibition on embryo development and quality, in vitro-produced zygotes $(n=352$, four replicates) were cultured in the absence or in the presence of $10 \mu \mathrm{M}$ LY294002. Embryo cleavage and development and blastocyst cell number were recorded as described above.

\section{Experiment 4: regulation of serine phosphorylation of GSK3A/B after GSK3 and PI3K inhibition}

To study the effect of GSK3 and PI3K inhibitors on GSK3 phosphorylation, two-cell embryos were treated with $\mathrm{LiCl}$

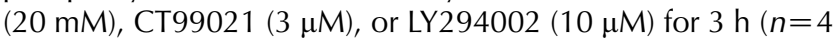
replicates). Subsequently, 35 embryos were loaded and resolved by SDS-PAGE in a $10 \%$ acrylamide gel. Immunoblotting was performed using specific antibodies that recognized phosphorylation at Ser21 and Ser9 of GSK3A and GSK3B respectively (1/1000 dilution, incubation overnight at $\left.4{ }^{\circ} \mathrm{C}\right)$.

\section{Experiment 5: $\beta$-catenin phosphorylation: detection in bovine embryos and regulation of Ser45 phosphorylation by LiCl, CT99021, and LY294002}

To study $\beta$-catenin phosphorylation, day 8 blastocysts $(n=30)$ were loaded and resolved by SDS-PAGE in a $10 \%$ acrylamide gel. Immunoblotting was performed using specific antibodies against $\beta$-catenin phosphorylated at Thr41, Ser33/37-Thr41/Ser45-Ser552 and Ser675 (1/1000 dilution, incubation overnight at $4{ }^{\circ} \mathrm{C}$ ). To investigate the 
phosphorylation of $\beta$-catenin on Ser45, two-cell embryos, after being treated with LY294002 $(10 \mu \mathrm{M})$, LiCl $(20 \mathrm{mM})$, or CT99021 $(3 \mu \mathrm{M})$ for $3 \mathrm{~h}$, were loaded and resolved by SDSPAGE in a $10 \%$ acrylamide gel. Immunoblotting was performed using the specific antibody against $\beta$-catenin phosphorylated at Thr41/Ser45 (1/1000 dilution, incubation overnight at $4{ }^{\circ} \mathrm{C}$; $n=4$ replicates).

\section{Statistical analysis}

Data obtained from densitometry of protein bands and comparison between different treatments of bovine embryo development were analyzed by ANOVA. All statistical analyses were carried out using SPSS versus 15.0 software package for Windows (SPSS Inc., Chicago, IL, USA). Differences between groups were considered significant when $P$ values were $<0.05$.

\section{Declaration of interest}

The authors declare that there is no conflict of interest that could be perceived as prejudicing the impartiality of the research reported.

\section{Funding}

This work was supported by Science Foundation Ireland (grant number 07/SRC/B1156; the opinions, findings, and conclusions or recommendations expressed in this material are those of the authors, and do not necessarily reflect the views of the Science Foundation Ireland). I M Aparicio was supported by a postdoctoral contract (POS07011) from Consejeria de Economia, Comercio e Innovacion, Junta de Extremadura, Spain. M García Herreros was funded by a Post-doctoral contract (2008-0198) from the Spanish Government.

\section{Acknowledgements}

The authors thank Mary Wade for her excellent technical support in the IVF laboratory.

\section{References}

Aberle H, Bauer A, Stappert J, Kispert A \& Kemler R 1997 $\beta$-Catenin is a target for the ubiquitin-proteasome pathway. $E M B O$ Journal $\mathbf{1 6}$ 3797-3804.

Amit S, Hatzubai A, Birman Y, Andersen JS, Ben-Shushan E, Mann M, Ben-Neriah Y \& Alkalay I 2002 Axin-mediated CKI phosphorylation of $\beta$-catenin at Ser 45: a molecular switch for the Wnt pathway. Genes and Development 16 1066-1076.

Aparicio IM, Bragado MJ, Gil MC, Garcia-Herreros M, GonzalezFernandez L, Tapia JA \& Garcia-Marin LJ 2007 Porcine sperm motility is regulated by serine phosphorylation of the glycogen synthase kinase3a. Reproduction 134 435-444.

Bagger PV, Byskov AG, Christiansen MD, Bang L \& Mortensen L 1993 Lithium stimulates the first meiotic division in mouse oocytes. Acta Obstetricia et Gynecologica Scandinavica 72 514-519.

Baluch DP \& Capco DG 2008 GSK3 $\beta$ mediates acentromeric spindle stabilization by activated PKC . Developmental Biology 317 46-58.

Bijur GN \& Jope RS 2003 Glycogen synthase kinase-3 $\beta$ is highly activated in nuclei and mitochondria. Neuroreport 14 2415-2419.
Cadigan KM \& Nusse R 1997 Wnt signaling: a common theme in animal development. Genes and Development 11 3286-3305.

Fahy MM \& Kane MT 1994 Effects of lithium chloride on rabbit blastocyst expansion, and accumulation of phosphoinositides and inositol phosphates. Journal of Reproduction and Fertility 100 347-352.

Fang X, Yu SX, Lu Y, Bast RC Jr, Woodgett JR \& Mills GB 2000 Phosphorylation and inactivation of glycogen synthase kinase 3 by protein kinase A. PNAS 97 11960-11965.

Fang D, Hawke D, Zheng Y, Xia Y, Meisenhelder J, Nika H, Mills GB, Kobayashi R, Hunter T \& Lu Z 2007 Phosphorylation of $\beta$-catenin by AKT promotes $\beta$-catenin transcriptional activity. Journal of Biological Chemistry 282 11221-11229.

Forde JE \& Dale TC 2007 Glycogen synthase kinase 3: a key regulator of cellular fate. Cellular and Molecular Life Sciences 64 1930-1944.

Frame S \& Cohen P 2001 GSK3 takes centre stage more than 20 years after its discovery. Biochemical Journal 359 1-16.

Frame S, Cohen P \& Biondi RM 2001 A common phosphate binding site explains the unique substrate specificity of GSK3 and its inactivation by phosphorylation. Molecular Cell 7 1321-1327.

Goode N, Hughes K, Woodgett JR \& Parker PJ 1992 Differential regulation of glycogen synthase kinase- $3 \beta$ by protein kinase $C$ isotypes. Journal of Biological Chemistry 267 16878-16882.

Harwood AJ 2001 Regulation of GSK-3: a cellular multiprocessor. Cell 105 821-824.

Hedgepeth CM, Conrad LJ, Zhang J, Huang HC, Lee VM \& Klein PS 1997 Activation of the Wnt signaling pathway: a molecular mechanism for lithium action. Developmental Biology 185 82-91.

Hino S, Tanji C, Nakayama KI \& Kikuchi A 2005 Phosphorylation of $\beta$-catenin by cyclic AMP-dependent protein kinase stabilizes $\beta$-catenin through inhibition of its ubiquitination. Molecular and Cellular Biology 25 9063-9072.

Holm P, Booth PJ, Schmidt MH, Greve T \& Callesen H 1999 High bovine blastocyst development in a static in vitro production system using SOFaa medium supplemented with sodium citrate and myo-inositol with or without serum-proteins. Theriogenology 52 683-700.

Jope RS 2003 Lithium and GSK-3: one inhibitor, two inhibitory actions, multiple outcomes. Trends in Pharmacological Sciences $\mathbf{2 4}$ 441-443.

Jousan FD \& Hansen PJ 2007 Insulin-like growth factor-I promotes resistance of bovine preimplantation embryos to heat shock through actions independent of its anti-apoptotic actions requiring $\mathrm{PI} 3 \mathrm{~K}$ signaling. Molecular Reproduction and Development 74 189-196.

Jousan FD, Oliveira LJ \& Hansen PJ 2008 Short-term culture of in vitro produced bovine preimplantation embryos with insulin-like growth factor-I prevents heat shock-induced apoptosis through activation of the phosphatidylinositol 3-kinase/Akt pathway. Molecular Reproduction and Development 75 681-688.

Kao KR, Masui Y \& Elinson RP 1986 Lithium-induced respecification of pattern in Xenopus laevis embryos. Nature 322 371-373.

Klein PS \& Melton DA 1996 A molecular mechanism for the effect of lithium on development. PNAS 93 8455-8459.

Laemmli UK 1970 Cleavage of structural proteins during the assembly of the head of bacteriophage T4. Nature 227 680-685.

Li P, Tong C, Mehrian-Shai R, Jia L, Wu N, Yan Y, Maxson RE, Schulze EN, Song H, Hsieh CL et al. 2008 Germline competent embryonic stem cells derived from rat blastocysts. Cell 135 1299-1310.

Manji HK \& Lenox RH 1999 Ziskind-Somerfeld Research Award. Protein kinase C signaling in the brain: molecular transduction of mood stabilization in the treatment of manic-depressive illness. Biological Psychiatry 46 1328-1351.

Manji HK, Potter WZ \& Lenox RH 1995 Signal transduction pathways. Molecular targets for lithium's actions. Archives of General Psychiatry $\mathbf{5 2}$ 531-543.

Meijer L, Flajolet M \& Greengard P 2004 Pharmacological inhibitors of glycogen synthase kinase 3. Trends in Pharmacological Sciences $\mathbf{2 5}$ 471-480.

Modina S, Abbate F, Germana GP, Lauria A \& Luciano AM 2007 -Catenin localization and timing of early development of bovine embryos obtained from oocytes matured in the presence of follicle stimulating hormone. Animal Reproduction Science 100 264-279.

Mork A \& Geisler A 1987 Mode of action of lithium on the catalytic unit of adenylate cyclase from rat brain. Pharmacology \& Toxicology 60 241-248. 
Murray JT, Campbell DG, Morrice N, Auld GC, Shpiro N, Marquez R, Peggie M, Bain J, Bloomberg GB, Grahammer F et al. 2004 Exploitation of KESTREL to identify NDRG family members as physiological substrates for SGK1 and GSK3. Biochemical Journal 384 477-488.

Rao AS, Kremenevskaja N, Resch J \& Brabant G 2005 Lithium stimulates proliferation in cultured thyrocytes by activating $W n t / \beta$-catenin signalling. European Journal of Endocrinology 153 929-938.

Ring DB, Johnson KW, Henriksen EJ, Nuss JM, Goff D, Kinnick TR, Ma ST, Reeder JW, Samuels I, Slabiak T et al. 2003 Selective glycogen synthase kinase 3 inhibitors potentiate insulin activation of glucose transport and utilization in vitro and in vivo. Diabetes 52 588-595.

Rogers I \& Varmuza S 1996 Epigenetic alterations brought about by lithium treatment disrupt mouse embryo development. Molecular Reproduction and Development 45 163-170.

Roy L, McDonald CA, Jiang C, Maroni D, Zeleznik AJ, Wyatt TA, Hou X \& Davis JS 2009 Convergence of $3^{\prime}, 5^{\prime}$-cyclic adenosine $5^{\prime}$-monophosphate/protein kinase $A$ and glycogen synthase kinase- $3 \beta / \beta$-catenin signaling in corpus luteum progesterone synthesis. Endocrinology 150 5036-5045.

Schlesinger A, Shelton CA, Maloof JN, Meneghini M \& Bowerman B 1999 Wnt pathway components orient a mitotic spindle in the early Caenorhabditis elegans embryo without requiring gene transcription in the responding cell. Genes and Development 13 2028-2038.

Seidensticker MJ \& Behrens J 2000 Biochemical interactions in the wnt pathway. Biochimica et Biophysica Acta 1495 168-182.

Stachel SE, Grunwald DJ \& Myers PZ 1993 Lithium perturbation and goosecoid expression identify a dorsal specification pathway in the pregastrula zebrafish. Development 117 1261-1274.

Stambolic V, Ruel L \& Woodgett JR 1996 Lithium inhibits glycogen synthase kinase-3 activity and mimics wingless signalling in intact cells. Current Biology 6 1664-1668.

Taurin S, Sandbo N, Qin Y, Browning D \& Dulin NO 2006 Phosphorylation of $\beta$-catenin by cyclic AMP-dependent protein kinase. Journal of Biological Chemistry 281 9971-9976.

Uzbekova S, Salhab M, Perreau C, Mermillod P \& Dupont J 2009 Glycogen synthase kinase $3 \mathrm{~B}$ in bovine oocytes and granulosa cells: possible involvement in meiosis during in vitro maturation. Reproduction 138 $235-246$.
Vigneault C, McGraw S, Massicotte L \& Sirard MA 2004 Transcription factor expression patterns in bovine in vitro-derived embryos prior to maternal-zygotic transition. Biology of Reproduction $\mathbf{7 0}$ 1701-1709.

Vlahos CJ, Matter WF, Hui KY \& Brown RF 1994 A specific inhibitor of phosphatidylinositol 3-kinase, 2-(4-morpholinyl)-8-phenyl-4H-1-benzopyran-4-one (LY294002). Journal of Biological Chemistry 269 5241-5248.

Wakefield JG, Stephens DJ \& Tavare JM 2003 A role for glycogen synthase kinase-3 in mitotic spindle dynamics and chromosome alignment. Journal of Cell Science 116 637-646.

Wang X, Liu XT, Dunn R, Ohl DA \& Smith GD 2003 Glycogen synthase kinase-3 regulates mouse oocyte homologue segregation. Molecular Reproduction and Development 64 96-105.

Woodgett JR 1990 Molecular cloning and expression of glycogen synthase kinase-3/factor A. EMBO Journal 9 2431-2438.

Xu XY, Zhang Z, Su WH, Zhang Y, Feng C, Zhao HM, Zong ZH, Cui C \& Yu BZ 2009 Involvement of the p110 alpha isoform of PI3K in early development of mouse embryos. Molecular Reproduction and Development 76 389-398.

Yanagawa S, Matsuda Y, Lee JS, Matsubayashi H, Sese S, Kadowaki T \& Ishimoto A 2002 Casein kinase I phosphorylates the Armadillo protein and induces its degradation in Drosophila. EMBO Journal 21 1733-1742.

Yost C, Torres M, Miller JR, Huang E, Kimelman D \& Moon RT 1996 The axis-inducing activity, stability, and subcellular distribution of $\beta$-catenin is regulated in Xenopus embryos by glycogen synthase kinase 3. Genes and Development 10 1443-1454.

Received 21 January 2010

First decision 8 March 2010

Revised manuscript received 18 April 2010

Accepted 28 April 2010 